\title{
NOTE-TAKING AND LANGUAGE ACQUISITION ${ }^{1}$
}

\section{Debra Simmons}

Note-taking, by and large, is regarded as a means to an end. It is a process used to remember things that must be done, spoken of, or included in a written document or report. It is a skill used to collect and organize data. It is rarely thought of as a way to help students learn English. Yet the structure of notes and the procedure for taking notes may develop in ESL students the confidence to use English, to learn new words, and to understand new material through the relationships that become apparent through notes.

Templeton Secondary School is typical of schools in Vancouver, British Columbia. In the school there are almost 1400 students in grades 8-12, of whom two-thirds are from families where English is not the first language. There are over 30 different native languages represented in the school. This is not unique for Vancouver, where only $62 \%$ of grade 12 students were born in North America. The large proportion of those with varying degrees of fluency in English has given rise to an extensive ESL program. Templeton currently has almost 200 students in a multi-level program. Students enter the program at a point determined by their English language ability and move through the levels at a pace that is determined by their abilities. The students in the beginning ESL classes have entered the school with little knowledge of English. Students at the transitional level, the most advanced, are learning the nuances of the English language, poised to enter the regular school program.

At Templeton, a program was established through the library which exposed students in regular classes to a series of sequential lessons in research skills. Working co-operatively with the teachers of Grade 8 Social Studies, Grade 9 Science and Grade 10 English, all students are taught a set of skills related to location, organizing, and using information. The skills are taught grade-wide and are sequential and dvelopmental. The program was originally developed to overcome the hit and miss approach to teaching research skills. The intent was to reach every student through this grade-wide program. It didn't. All the "mainstreamed" or "normal" students went through the program, but the students who needed the program the most, students in special classes, including all levels of ESL, were overlooked. It was discovered that when a student passed through the ESL program into regular classes, they suffered from a double handicap - language difficulties and a absence of research skills. Not only were they not getting the same instruction as other students but they frequently lacked basic library skills as well. If, before coming to Canada they attended school at all, the schools did not have access to the 
informational resources, materials, and personnel with which Vancouver's schools are blessed. Many have had no experience with libraries and research. Not only do ESL students have to be taught the same skills as those taught to students in the regular program, but they must be provided with the same basics taught to students in Canadian elementary schools. As a result, a scope and sequence of skills for ESL students was created with the help of the ESL teachers. In it are included skills which, it is assumed, all grade 8 students possess: familiarity with the card catalogue, an understanding of the arrangement of materials in the library, an awareness of reference materials, an appreciation of the lending nature of library materials, use of guide words, a knowledge of parts of a book and their function and alphabetization.

The progression of research skills taught at Templeton to the regular classes begins in grade 8 Social Studies with learning to take notes from reference materials, primarily encyclopedias. This skill is even more important to ESL students since its benefits are so many and the technique can be so easily learned. It is a process that is adaptable to language ability and teaching situation as well as to subject matter. It builds on strengths and develops confidence. It circumvents many of the language problems faced by students learning English since notes can be derived from pictures as well as printed materials.

Of primary importance to the skill of taking notes is the rule that no material may be copied from a book. This means that the words that become notes are generated from the students' vocabulary or once their meaning is learned, become part of the students' vocabulary. It insures understanding, since the information must be processed by the students before a note can be made. Since only the most important information becomes a note, the students must be able to understand the material sufficiently well to determine its importance. Since the information in the notes is to be relevant to the specific subject and the areas in which data is to be gathered, the students must be able to discriminate between what is and is not relevant to their needs. This is very important to students who are working in a foreign language who invariably must work harder and spend more time than the native speaker in order to understand. They must be able to locate what they need and ignore the irrelevant. They have neither the aptitude nor the time to read everything.

Taking notes helps students to organize information. Since the information taken as a note shares a physical proximity to the subject of the note, relationships can be better understood by students with language problems. This helps to develop the skill of using context clues to understand words. If, for example, the word "camouflage" appears in the note concerning the protection of a specific animal, the location of that word under the heading "protection" will help the students remember the 


\section{Diagram 1}

Research and Study Skills

\section{E.S.L. DEPT.}

\section{Locates Information}

1. understands how things are arranged in the library

2. uses the card catalogue

3. follows directions

4. knows that reference material exists

5. uses guide words

6. uses and understands parts of a book

II. Acquires and Analyzes Information

1. can take simple notes

2. can use atlases, stations

3. locates information in a book (Physiology Station)

4. uses graphs and tables

5. comparative use of encyclopedias, dictionaries, almanacs

6. encyclopedia evaluation

7. can take complete notes and organize these to make a presentation oral/written

8. prepares a bibliography

9. uses periodical indexes

\begin{tabular}{|c|c|c|}
\hline E.S.L. & E.LA. & Transitional \\
\hline Int/Beg & & \\
\hline \multicolumn{3}{|l|}{ Int } \\
\hline \multicolumn{3}{|l|}{ Int } \\
\hline \multicolumn{3}{|l|}{ Int/Adv } \\
\hline \multicolumn{3}{|l|}{ Int/Adv } \\
\hline & $x$ & \\
\hline & $\mathrm{X}$ & \\
\hline & $\mathrm{X}$ & \\
\hline & & $X$ \\
\hline & & $\mathrm{X}$ \\
\hline & & $\mathrm{X}$ \\
\hline & & $X$ \\
\hline & & $\mathrm{X}$ \\
\hline & & $\mathrm{X}$ \\
\hline
\end{tabular}

meaning of the word, since it is no longer a word in isolation. Lastly, taking notes is important to ESL students because it forces them to take key words and construct complete sentences from them. The complexity and sophistication of the sentences will reflect the ability of the student. For beginning students, each note might become a complete sentence. This gives rise to simple paragraphs made up of a series of simple senten- 
ces, but the vocabulary is understood by the students and the sentences are created by the students. For the more advanced students, more complex sentences might be required using the devices of combining words, parenthetical expressions, and introductory phrases. Learning to manipulate the data to construct a variety of sentences different in length and/or construction is a useful exercise for students. Since the language of the material from which the information is taken, the vocabulary of the note and the students' written report can be geared to the ability of the students, all ESL students regardless of language ability can succeed. They gain confidence in their ability to extrapolate data, to take notes using words that they can understand, and to use those notes to write a report fulfilling the requirements established by the teacher. They gain confidence in their ability to use their new language - English.

The process for teaching the skill of note-taking is not overly complex, but it must be developmental and consistent. At an introductory level, a teacher might read to the class or have the students read a simple exercise. The ESL teachers at Templeton frequently use materials from The Westcoast Reader: A Newspaper for People Who Are Learning to Read English. Using a note-taking sheet created with a specific article or exercise in mind, the students put words from the article into an appropriate area on the paper. For example, a note-taking sheet for an article on "December Festivals and Special Days" would have space allocated on it for the holidays mentioned in the article. Words such as "eight nights", "Swedish", and "festival of lights" would be written into the section dealing with Hannukah, Christmas, and St. Lucia's Day. This introduces the basic idea of taking notes: key words, main ideas, organization of information, limited subject, relevance, and accuracy. The use of abbreviations to make notes quick and brief can also be introduced at this time. In addition to the skill of taking notes, listening skills can be reinforced. This type of exercise can be repeated over and over again by the classroom teacher.

Once students have a grasp of the basic concepts of taking notes, they are then introduced to the more complex problem of gathering information from library materials. This is more difficult because there is not always as obvious a structure to materials not aimed at ESL students, there is information that does not apply to the immediate needs of the students, the vocabulary is not always familiar and more data must be manipulated. Students must be shown how to move to this more complex procedure, using the skills they have already acquired.

To overcome this gap in what the students can do and what they are now asked to do, a model has been created which shows the ESL students the steps they are to follow. They are then asked to mimic the model. The end product for a beginning ESL class is a paragraph which describes five specified aspects of an animal or insect. For the advanced transitional 


\section{Diagram 2}

December Festivals and Special Days (Page 1)

\section{Note-taking Exercise}

1. Teacher distributes note-taking sheet (below).

2. Teacher reads about each festival to class. Students just listen. (They do not have the paper in front of them.)

3. Students copy notes into appropriate festival boxes.

4. Class discusses correct placement of notes.

5. Students write a brief paragraph about each festival in their own words based on their chart notes.

6. Students write a brief 3-4 sentence paragraph about a festival from their own country or another festival they know about.

7. Students read paragraphs onto a cassette tape. Play back. Rest of class takes notes on each student's festival paragraph.

\section{FESTIVAL}

\section{HANNUKAH}

ST. LUCIA'S DAY

\section{CHRISTMAS DAY}

\section{ST. NICHOLAS DAY}

\section{NOTES}

European countries

birth of Jesus

lighting a candle

Jewish

children's day

eight nights

Swedish

Christmas Eve/church

cold, dark winter

festival of light

IN THE CLASSROOM/EN CLASSE 
students, the end product is usually an oral report in which the areas to be discussed are generated by the students instead of by the teacher. Regardless of the level, regardless of the program, ESL or regular, students at Templeton are asked to follow a given format and procedure for taking notes. What changes is not the form or procedure, but the complexity of the note, the vocabulary, the sources of information, and the sophistication of the final product.

The model begins with a passage from the Raintree Illustrated Science Encyclopedia. Associated with this passage, the students are given a sheet for taking notes. The sheet is divided into the five areas: kind of animal, appearance, food, habitat, and locomotion. The class reads a selection, such as the "Slug" and, sentence by sentence, decides two things: Is the information important? Where on the note sheet should the important data be entered? If it is decided that the information is important enough to constitute a note, then the form of the note is reviewed. Based on their previous experience with notes, they are reminded that notes incorporate key words only, are brief, and use abbreviations when possible. Step-bystep, sentence by sentence, the process is repeated until the paragraph is finished and there are brief, accurate and relevant notes in each of the five sections of the note sheet. Using the information on the sheet only, the students then are asked to write a paragraph about the slug providing information about the locomotion, habitat, food, appearance and kind of animal. At this time additional instruction might be given about sentence formation, subject-verb agreement, the need to spell accurately, etc. The students may begin their paragraph at any point on the sheet. There is no need to begin with kind of animal. A student might choose to begin the paragraph with habitat or appearance. This gives the students experience in manipulating data to achieve a variation in the final product.

Following the model, students then begin an exercise on another animal. The animals from which the selection is made are drawn from the Raintree Encyclopedia or another encyclopedia with a controlled vocabulary. For the beginning ESL classes, animals are selected for which an illustration exists so that information may be derived from pictures as well as from words. Each student is given a different animal. A sheet similar to the one used in the model is given to each student for their notes. The sheet has no words to identify the five areas of concern. The students must write in these words. This is an important step for it reminds the students what is relevant to their needs. Once again, the final product is a paragraph about an animal in which all the areas of concern are discussed.

At Templeton the model is an animal. Animals were chosen through consultation with the ESL teacher, but had the teacher wanted to begin research work in a different area, such as Social Studies instead of Science, a similar model would have been constructed. What is worth repeating is 


\section{Diagram 3}

Note-Taking

Encyclopedia entry: Raintree Illustrated Science Encyclopedia, 1984. Vol. 17 p. 1548.

SLUG (slog) slug is the name for any snail (class Gastropoda) that has a very small shell, or has no shell. The animal has two pairs of tentacles, with eyes on the outer end of the longer pair. The great gray slug (Limax maximum) is about $9 \mathrm{~cm}$ (4 in) long. Like most slugs, it is a vegetarian. But the great gray slug is a pest. It eats plants and damages many crops. Most types of slugs feed on decaying matter. Many feed on fungi. Food is usually taken in with the tilelike tongue, or "radula." Slugs are usually active only at night or after rain. They hide during the day under stones and vegetation. J.J.A./C.5.H.

\section{ELA: NOTE-TAKING}

Name

Topic:

Block:

1. Take notes using strips supplied below

2. Use only main ideas and key words

3. Complete and hand in 4 note strips for marking

4. Write an in-class paragraph using only these notes

Kind

Appearance

Food 
Habitat

Locomotion

that although the model or subject may change, the procedure remains the same. It follows and builds on the beginning exercises done in class and can itself be built upon at a later date. Regardless of future subjects, the procedure for taking notes that are accurate, brief, relevant, organized, and that employ key words is always the same.

\section{CONCLUSION}

ESL students must be provided with as many skills as possible to make their acquisition of English and their passage through school as easy as possible. Note-taking is such a skill. It provides the students with an approach to evaluate, manipulate, and organize information while developing vocabulary, confidence, writing and listening skills in English. Research shows that "When teachers explain exactly what students are expected to learn, and demonstrate the steps needed to accomplish a particular academic task, students learn more."2 Teaching ESL students to take notes provides them with a skill useful in their immediate and future academic work as well as teaching them approaches to learning English as an additional language.

\section{FOOTNOTES}

1. The program that has been developed in the Templeton Resources Centre could not have come about without the contributions, input, and interest of my colleagues Wendy Shaw, teacher-librarian at Templeton, Ann Shorthouse, Judy Robertson, and Eileen LeGallais, teachers in the ESL program at Templeton.

2. What Works: Research About Teaching and Learning. 1986. Washington, D.C.: United States Department of Education. p. 35.

\section{REFERENCES}

Raintree Illustrated Science Encyclopedia. (1979). Milwaukee: Raintree.

What Works: Research About Teaching and Learning. (1986). Washington, D.C.: United States Department of Education. 


\section{THE AUTHOR}

Debra Simmons is currently a teacher-librarian at Templeton Secondary School in Vancouver, British Columbia. She works in a school with an active and growing ESL department whose teachers are interested in cooperatively planning and teaching the kind of units described in the article. Mrs. Simmons has been a classroom teacher and a teacher-librarian in both elementary and secondary schools in the U.S. and Canada and has described aspects of the library program in articles that have appeared in library-related journals: Emergency Librarian and School Libraries in Canada. 